\title{
Investigating Sentence Fragments in Comic Books: A Syntactic Perspective
}

\author{
Herman $^{1}$, Nguyen Van Thao ${ }^{2}$, \& Naomi Anggraini Purba ${ }^{1}$ \\ ${ }^{1}$ English Education Department, Universitas HKBP Nommensen, Medan, Indonesia \\ ${ }^{2}$ Faculty of Philology, Hanoi Pedagogical University 2, Vinh Phuc, Vietnam \\ Correspondence: Nguyen Van Thao, Faculty of Philology, Hanoi Pedagogical University 2, Vinh Phuc, Vietnam.
}

Received: July 12, $2021 \quad$ Accepted: September 1, $2021 \quad$ Online Published: September 3, 2021

doi:10.5430/wjel.v11n2p139 URL: https://doi.org/10.5430/wjel.v11n2p139

\begin{abstract}
This research is aimed to analyze sentence fragments in a comic. The main research questions raised in this paper are: What types of sentence fragments can be seen in comic Hunter X Hunter by Yoshihiro Togashi 1998? What factor types can be found in comic Hunter X Hunter by Yoshihiro Togashi 1998? The paper uses the qualitative method to conduct content and document analysis (Choy \& Clark, 2010). The source of data was the comic entitled 'Hunter X Hunter in which the researchers discovered six forms of Sentence Fragments after studying the data: fragments of adjective clause, adverbial clause, nominal clause, appositive, infinitive clauses, missing subject, participial, and prepositional phrase fragments. The information was gathered from 30 chapters of Yoshihiro's comic. There were 34 Sentence Fragments, 13 (38\%) Dependent clause fragment, 21(62\%) into-phrase fragment. There are 6 types of sentence Fragment factors that were investigated by Bashir (2016), but in this comic only 4 factors were found; namely, Omission of the Verb (50\%), Subject (20\%), and Object (10\%), omission of both subject and verb (10\%), and Appositive or list Fragments (10\%).
\end{abstract}

Keywords: analysis, syntax, sentence fragment, conversation, comic

\section{Introduction}

Language is a system of communication that consists of a set of sounds and written symbols that people in a specific country or region use to communicate while speaking or writing. Language, according to Liasari (2015) is the most important aspect of human life. People may convey their emotions, ideas, and intentions, among other things. On the other side, Herman (2016) claims that language is utilized as a form of communication since it allows us to communicate with our friends, express our thoughts, and convey our emotions (Van Thao, Herman, Ha, Thuy, \& Tho, 2020). On the basis of that argument, it can be stated that language is an important instrument for humans to communicate with one another, and that people may express their ideas, experiences, thoughts, needs, hopes, feelings, and so on to one another through language.

Talking about language, the world has many types of languages, one of which is English, which has grown and become a global language. According to Herman (2017), English is an international language used by the world community to communicate and establish relationship with people from different countries in all over the world. According to Sinaga, Herman, and Pasaribu (2020), the importance of English can be seen from various sides of life; for example, job requirement. One of the requirements is language competence, both of spoken and written form. This means that English language becomes the most essential language in the world because people from many different countries use it to communicate. In some countries, English language has a status of foreign language that should be learnt and mastered by students. English language has been taught on a high level and became a compulsory subject in grade school all over the world.

Like other languages, learning of English language requires the mastery of four skills; those are listening, writing, reading, and speaking which are interconnected each other. Listening and reading are receptive skills while speaking and writing are productive skills (Herman, 2017). Writing is considered as a complex skill. As the complex skill, writing needs not only a lot of vocabulary but correct grammar. Writing is a means of visually conveying language. Writing systems use a collection of symbols to represent speech sounds, as well as punctuation and numerals, among other things. Writing is a partial depiction of Units of language expression, according to Lado (1964), as mentioned 
in Pardede and Herman (2020). Students are frequently requested to provide definitions of essential words and phrases in academic work to demonstrate to their instructors that they fully comprehend these terminologies. Academic authors, on the other hand, usually define terminology so that their readers know exactly what they're talking about when certain crucial keywords are used. When crucial words are not comprehended clearly, misinterpretation might occur. It is not enough for all pupils to focus solely on oral communication; they must also be able to write in the target language.

Writing is a productive talent, according to Herman, Purba, Thao, and Purba (2020), because the focus is on providing information. From this statement, it can be concluded that English is an important global language used in the international interaction and communication, and writing skill should be mastered in order to make this communication more effective.

Writing, of course, necessitates complete and proper sentences; syntax is the study of the relationship between language and sentence structure. Syntax is the study of the concepts and procedures that are used to generate sentences in different languages. The purpose of a syntactic examination of a particular language is to create a grammar that can be viewed as a device of some sort for constructing the sentences of the language under inquiry. According to Chaer (2009) in Mahayani, Chodijah, and Ainiyah (2018), syntax is a language subsystem that studies word arrangement and combining them into bigger units. Syntactic units are words, phrases, clauses, sentences, and passages. On the other hand, according to Syamsuddin (2007) in Mahayani et al. (2018), Syntax or also called the study of word order, describes the relation between language elements to form a sentence. Every element in syntax is understood through its function in a system. The function of a syntactic unit occurs if the unit appears in a formation; for example, words formation in a phrase, phrase formation in a clause, clause formation in a sentence. Anker (2010) stated that a good sentence has 3 elements, which are: a subject, verb, and complete thought. When a sentence comprises at least a subject and a verb, it means that the structure of the sentence is equally significant for others in understanding the statement. The reader may find it difficult to understand the meaning/message delivered by the sentence if the structure is improper.

One of the incomplete sentences is called a sentence fragment. Fragment is like a phrase or it may be a dependent clause that can run as a sentence. A fragment expresses an incomplete thought; a fragment cannot function as a simple sentence. It is commonly called as an unfinished sentence that cannot create a complete meaning. Fragments are usually parts of sentences that have got separated from the main clause. Removing the period between the fragment and the main sentence is one of the simplest ways to fix them. For the newly joined sentence, further punctuation may be required. Sentences that have an incomplete sentence or sentence structure are called sentence fragments. According to Greenbaum \& Nelson (2002:3) as cited in Nurhusna (2012), A sentence fragment is a group of words punctuated as a sentence despite the fact that it is not grammatically complete. A sentence provides a complete though whereas a fragment fails to inform the reader about the topic (the subject) or what happened (the verb) (Fulwiler \& Hayakawa, 2003:3 as cited in Nurhusna (2012)). As a result, a sentence fragment is regarded as an incomplete thought, according to Oshima and Hogue (1998:169) and stated in Yaqin (2020), if a dependent phrase is not related to an independent phrase, rendering the phrase unable to convey a complete thought. Bram (1995:26) cited in Yaqin (2020) also agrees that a sentence fragment is similar to a phrase or a dependent clause. It expresses an incomplete thought and cannot function nor stand alone as a simple sentence. Researchers can deduce from the foregoing that a sentence fragment is a word group that attempts to function as a sentence but lacks one or more of the pieces required for a complete sentence. Bram (1995:26) as cited in Yaqin (2020), a sentence can be called a sentence fragment if it has the following characteristics: A sentence with no subject, A sentence with no verb, A sentence with no subject and verb, A sentence with no main or independent clause.

One of the functions of the English language that we find in our lives is in literature. In English, literature refers to literary works that are normally written on paper, such as novels, short stories, comics, and so on. According to Hutabarat, Herman, Silalahi, and Sihombing (2020) there are three sorts of literary works that are utilized as references in learning activities,-in their article. Dissertations, journals, and research reports are examples of primary literature that contain ideas or new hypotheses. Second, public collection like some books such as novels, comics, serials, short story, etc. Third, secondary literature; usually in this type of literature theories or ideas tend not to explain the new findings; some include abstracts, encyclopedias, magazines, newspapers, and manuals. Researchers focus on secondary literature, namely comic.

Comic is a literary work in the form of a story written with images, where there is one character who is favored. Comics generally contain fictional or unreal stories. Masdiono (1998:11) as cited Soedarso (2015) defines comic as a story in the form of contiguous pictures. It implies the idea of a media visual with a group of pictures and words, and 
images in a comic are defined as static images arranged sequentially and interconnected between each other. Collier's Encyclopedia in Salor and Marasligil (2013) defines the term "comic" as referring to a collection of tightly related, highly engaging drawings that differ from traditional cartoons in that they are not always lighthearted, but some artists make them serious, mysterious, and adventurous. From this explanation, it can be concluded that a comic is a pictorial story that is composed and interrelated and is fictional in nature, and in the story the character has their respective characters.

According to Arsyat (2014) comics have various characteristics: a. proposional character, which means that reading comics can emotionally involve the reader with the major characters in the story; b. Harsh comedy, which uses spoken and simple language to communicate with lay people; and c. Harsh humor, which uses spoken and simple language to connect with lay people. c. Conversational Language (Market Language), i.e., the use of colloquial language, will appeal to readers more, d. Morals or The Soul of the Doer is a simplification of conduct that describes Morals or The Soul of the Doer. In the story comics, behavioral patterns are often simple and predictable. Heroic in nature, comic content tends to carry readers to adore its heroes. In comics, the reader will know what kind of comic he or she reads, and what storyline the comic writer conveyed, so that readers can clearly see what is happening in the story based on the storyline, but oftentimes readers don't pay attention to the sentence structure that is included in a comic whether the sentence structure is correct or not (Nurhusna, 2012; Wu and Pei, 2018).

According to the researchers, Indonesians read Indonesian comics more often than English comics because their ability to read, speak, and write English is still limited, and their grammar skills are also limited whether they are teenagers, adults, or the elderly. Some researchers do not even know whether the sentence structure in English comics is right or not based on the guidelines of English sentences, which contain three vital aspects (Subject, Verb, and even complete thought). As a result, most Indonesians are unaware of what the lesson entails when it comes to writing incomplete sentences and what causes a sentence to be incomplete (sentence fragments). As a result of this problem, the researchers set out to explore the types and factors of sentence fragments found in a comic, specifically in Yoshihiro Togashi's Hunter X Hunter 1998, since the prior comics have never been investigated with the variables (subject) so that readers and other Indonesians will be aware of it as a result of our research.

The examples of using sentence fragments are written bellow. They are taken from Hunter X Hunter comic. The example is "time to keep" your end of the deal aunt mito Yoshihiro Togashi 1998.

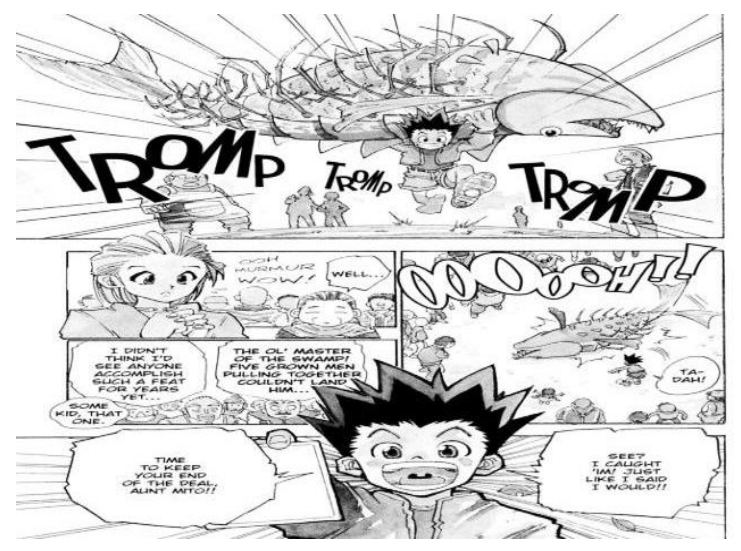

The researchers took this example based on the type of sentence fragment described by Choy and Clark (2003) in Nurhusna (2012), which is a type of sentence fragment, infinitive phrase fragment. The researchers chose the example since the definition of this fragment is a combination of the word 'to' plus a verb, and the the phrase 'to keep' appears in the example the researchers created.

Based on the example above, the researchers are interested to analyze the sentence fragments contained in the Hunter X Hunter comic. Previously, research on sentence fragments had been studied by Bashir, Yusof, Ahmad, and Syed Umar (2016) in his journal entitled "Sentence Fragment Analysis in the Writing of High School Students in Gwale, Kano, Nigeria. " This study is focused on empirical research gleaned from senior student compositions, which can be referred to as the object of research. The aim of this research is to identify the sentence fragments produced by seniors of secondary schools in their writing and the study uses a mixed methods approach, where an embedded design is adopted to guide data collection and analysis. Research object was 30 students who were purposefully selected from secondary schools in Gwale Local Government Area, Kano Nigeria. Achievement tests were used to 
collect data. Markin software version 4.222 was used to speed up the data analysis process.

Finally, based on the explanation above, the researchers embarked on the analyses of the sentence fragments in a comic titled as "An Analysis of Sentence Fragments in comic Hunter x Hunter by Yoshihiro Togashi 1998".

\section{Theoretical Review}

\subsection{Syntax}

Writing requires complete and correct sentences, and the study focusing on the relationship between language and sentence structure is called syntax. The study of the principles and procedures by which sentences are created in specific languages is known as syntax. The purpose of a syntactic examination of a given language is to build a grammar that can be viewed as a device for constructing the sentences of the language under inquiry. According to Chaer (2009) in Mahayani et al. (2018), syntax is a language subsystem that studies word arrangement and combining the words into bigger units. Syntactic units are words, phrases, clauses, sentences, and passages. On the other hand, according to Syamsuddin (2007) in Mahayani et al. (2018), syntax or also called the study of word order describes the relation between language elements to form a sentence. Every element in syntax is understood through its function in a system. As mentioned above, Anker (2010) stated that a good sentence has 3 elements, they are: a subject, a verb, and a complete thought. A sentence can be meaningful and be understood by reader when it has at least a subject and a verb. From the explanation above, it can be said that syntax is a science that studies the formation of a phrase into a sentence. To make a good and correct sentence, 3 elements are needed: namely, a subject, verb, and complete thought.

\subsection{Sentence Fragments}

\subsubsection{The types of Sentence Fragments}

According to the Choy and Clark (2010), Yang (2019) and Al Kayed, Khalaf, and Akram (2020) there are several types of sentence fragments including those with:

\section{a) Dependent Clauses}

A dependent-clause fragment, according to Choy and Clark (2010) in Nurhusna (2012), is a set of words that contain both a subject and a predicate and are part of a primary independent sentence but are separated from it with a period so that it stands alone. A dependent-clause fragment always begins with a subordinating conjunction. Kolln and Funk (2003) in Nurhusna (2012) state that a dependent clause fragment can be classified into the following subtypes: adjectival-clause fragments, adverbial-clause fragments, and nominal-clause fragments.

\section{- Adjectival - Clause Fragments}

An adjective clause, also called a relative clause, is a clause introduced by a relative pronoun (who, which, that) or a relative adverb (when, where, why) that generally modifies a noun (Kolln \& Funk, 2011). According to Choy and Clark (2010), an adjectival-clause fragment serves the function of an adjective which describes a noun or pronoun in the detached main clause or sentence that precedes the fragment.

In the following made-up example: I got dragged around the whole night meeting aunties and uncles. Who I'm pretty sure can't remember my name anyway.

\section{- Adverbial Clause Fragments}

An adverbial clause fragment begins with the subordinating conjunctions that are used to start adverb clauses, which describe verbs by stating how (as if, as if), when (after, as, as soon as, before, until, when, whenever, while), where (where, wherever), why (because, in order that, since, so that), and under what conditions (although, as long as, even though, if, though, unless) the action occurs (Choy \& Clark, 2010)

The following is a made-up example of it: I've been to English-speaking countries. Such as, Australia, England, Singapore, and the United States.

- Nominal Clause Fragments

Subordinate clauses with a range of functions similar to noun phrases are known as nominal clauses (Greenbaum \& Nelson, 2002 in Nurhusna (2012)). Detached from its main or independent clause, a nominal clause fragment begins with a that-clause or a WH-clause and can function as direct object.

In the following made-up example, the fragment begins with a that-clause and functions as direct object to the verb "realize" in its preceding sentence: They realize that the man can be a big-time threat to them. That 
he can take them all down easily.

b) Phrase Fragments

Stilman (1997) in Nurhusna (2012) states that a phrase is a collection of connected words that does not qualify as a clause because it lacks both a subject and a predicate (it may contain a noun, a verb or both, but these do not constitute a clause unless they are in a specific relation to each other). Like a dependent-clause fragment, a phrase fragment is detached from its main or independent clause so it stands on its own. In the following section, the subtypes of phrase fragments are discussed.

- $\quad$ Added Detail Fragments

The added-detail fragment contains an example or other detail that adds information to the preceding sentence. Detached from the main or independent sentence, this fragment lacks both a subject and predicate.

The following is a made-up example of it: After having a heated argument with her parents, she left her house. And took a cab to a friend's place.

- Appositive Fragments

An appositive is a statement that is placed next to a noun to help clarify its meaning. Appositive comes from the verb apposite, which means "to put things next to each other." An appositive fragment is detached from the preceding noun so it stands on its own, looking as if it were a sentence.

The following is a made-up example of it: The guy talking with Jake is a student. A law student with superior academic record and outstanding leadership skills.

- Infinitive Phrase Fragments

An infinitive is formed when the word to is combined with a verb, such as to walk or to study. Although further words will be added to complete the phrase, the notion will not be completed by a main clause because the main closure is separated from it.

The following is a made-up example of it: She wants to go to the garden. To catch butterflies for her biology project.

- Missing - Subject Fragments

The missing-subject fragment has a missing subject and is detached from the main or independent sentence. It usually begins with a coordinating conjunction.

For example: Although it has been many years, Chase still remembers that street. Near the river bank.

- Participial Phrase Fragments

A participle is the first word in a participial phrase. A participle is a form of a verb that also serves as an adjective. There are two types of participles: adverbial and adverbial participles by adding -ing to the primary verb, present participles are generated (e.g., laughing, waiting, talking). Past participles end in a-ed (e.g., laughed, waited, talked) or various past-tense forms of irregular verbs (e.g., slept, seen, sung).

For example: A school bus carrying twenty-five high school students crashed into a tunnel. Injuring the driver and fifteen students.

- Prepositional Phrase Fragments

Prepositions are brief words in our language that show the relationship or position between two words, such as on, near, by, under, behind, about, and so on. They must always come before a noun or a pronoun. The object of the preposition is the word or pronoun that comes after the preposition. A prepositional phrase is a collection of words that include the preposition and its object. A prepositional phrase is separated from its main sentence and stands alone as a fragment.

\subsubsection{The Factors of Sentence Fragments}

According to Bashir et al. (2016), the causes of sentence fragments are divided into seven types, namely:

a) Omission of Verb

Omission verb is a sentence that has not entered a verb so that the sentence does not have a verb.

b) Omission of Subject

Omission subject is a sentence that has not entered a subject and so that the sentence does not have a 
subject.

c) Omission of both subject and verb

Omission subject and verb is a sentence that has not entered a subject and verb so that the sentence does not have a subject and verb.

d) Omission of object

An omission object is a sentence that does not have an object because it does not contain a verb.

e) Dependent clause fragment

Because it does not express a complete notion, a dependent clause (or subordinate clause) cannot stand alone as a complete sentence.

f) Appositive or list fragment.

A noun phrase that renames and clarifies another noun is known as an appositive. Because an appositive can be somewhat long, it's common for authors to misinterpret it as a complete sentence. An appositive, on the other hand, is a fragment on its own.

\subsection{Comic}

\subsubsection{Definition of Comic}

Comics are a visual media for expressing ideas, often in combination with text or other visual information. A succession of juxtaposed panels is a common format for comics. Speech balloons, subtitles, and onomatopoeia are frequently used to indicate conversation, narration, sound effects, or other information. The speed of the story is aided by the size and layout of the panels. The most prevalent drawing technique in comics is cartoon and comparable forms of illustration; 'fumetti' is a genre that incorporates photographic imagery. Comic strips, editorials, jokes, and comic books are all common types of comics. Compiled volumes such as graphic novels, comic albums, and tankbon have become increasingly popular since the late twentieth century while webcomics have blossomed in the twenty-first.

There are many definitions of comics that have been stated by experts around the globe, including visual literature (Bonnef in Soedarso (2015)), and here are some of the definitions of this literary genre.

Masdiono (1998) cited by Soedarso (2015) defines a comic as a story told in a series of drawings. It connotes the concept of a media visual consisting of a collection of images and words. In art, comics are defined as static images arranged sequentially and these static images are interconnected between each other to form a story. In Salor and Marasligil (2013), Collier's Encyclopedia defines comedy as "a phrase assigned to a series or arrangement of closely related extremely engaging drawings that differs from the standard cartoon in that they are unduly serious, mysterious, and daring."

Based on the statement above, comics can be defined as written pictorial stories that are sequential to each other and can provide information to the reader. Comics is also an illustrated literary work, which are emerging in a variety of media. A story, time, characters, and so on are all present in comic books. Thus, this study looks at a comic with the goal of determining what kind of sentence fragments can be found in dialogs, as well as what causes sentence fragments to appear in this literary genre.

\subsubsection{Types of Comic}

According to Bonneff (2011:130) in Soedarso (2015), comics can be divided into four categories based on its form, namely comic strips, comic books (comic books), comics with the humor / adventure genre, biographical comics, and scientific comics. However, next comes the graphic novel, which combines several different stories in one book and web comics or online comics also appear in the literature:

a) Comic Strip

Comic strips are comics with only a few pictures. The images that are presented with a few ideas that exist in the comic are also few. Even though it only uses a few pictures and writing, it describes a complete picture. This comic strip is often found in newspapers and magazines because it is a place to load comics if it is in newspapers or magazines so that the limited stories and pictures are summarized and only present the main points.

b) Comic Book 
This type of comic is the most common type of comic. Book comics are comics that present a complete story in one book. In addition, there are usually series of each title that feature stories in a sustainable manner. However, there are also types of comic books that are unsustainable or serial, depending on the author, whether they finish the story in one or more books.

c) Comics with the humour / adventure genre

A humorous comic is a type of comic that presents a funny story that makes the reader laugh. The element of humor in humorous comics is contained in the inserted text or it can also come from pictures that are made funny. Unlike the comic humor genre, there is also an adventure genre in comics. This comic tells about the journey of the characters to find or fight for something. There are also actions that display images of battles between the groups of good and bad people.-

d) Biographical comics and scientific comics

Biographical comics usually feature the life story of an influential character who is presented in the form of a series of pictures or in the form of a comic. Although there are also types of biographical books that only display writings from stories of inspirational figures, it is different from that in biographical comics there are supporting pictures. Scientific comics are comics that contain a combination of narration and images. In scientific comics, there is more emphasis on stories that contain the process of discovering the latest products-such as stories of the discovery of the light bulb, the invention of the telephone and so on.

e) Online Comics (Webcomic)

This comic uses internet media as a medium for the primary source, and by using a website, this type of comic costs a relatively cheaper than purchasing the print media. This comic appeared along with the emergence of cyberspace in the world technology. Apart from print media such as newspapers, magazines, tabloids and newsletters, Internet media can be used as a means to publish comics. Internet space is more convenient for a wide audience because it has wider readership than the print media. Online comics can be used as a first step for publishing comics at a relatively higher cost but cheaper than print media.

\subsubsection{Genres and Categories of Comic}

Besides having several types of comics, it is also divided into several genre sections according to McCloud (2001) in Arifa (2016) including:

\section{a) Superhero}

Superhero comics, one of the most popular comic book genres, includes characters such as Superman, Batman, Spider-Man, and the X-Men, who wear capes and masks and utilize their amazing talents to protect humanity. Since the initial appearance of Superman in Action Comics, superheroes have captivated the public imagination. Superhero comics are generally seen as a modern type of mythology because of its emphasis on action, adventure, and memorable, iconic characters. While certain characters and series have been since the 1940s, new characters with unique abilities, outfits, and universes are created on a regular basis.

b) Manga

Manga is a Japanese-style trade paperback graphic novel that has recently exploded in popularity in the United States. Manga is divided into numerous categories that cater to different types of readers. Shojo (sometimes written Shoujo) is a Japanese drama and romance genre aimed towards young adolescent girls. Shonen manga is a type of manga that is mostly aimed at boys and offers hilarious storylines with a lot of action. Manga that is translated from Japanese is frequently printed so that it can be read from right to left in order to maintain the authenticity of the original. Manga publications are typically part of a series with multiple volumes, and they can be extremely addicting!

\section{c) Slice-of-Life}

Many comics and graphic novels depict actual life in insightful ways. These can take many different forms, including autobiography, romantic drama, and historical fiction, to name a few. Slice-of-life comics are popular among older teenagers and people looking for a relaxing read.

\section{d) Humour}

There are a lot of comics that live up to their moniker. From Mad Magazine to Simpsons Comics to editorial cartoons, comics are a terrific place to find exaggeration, sarcasm, and outright silliness. 


\section{e) Non-fiction}

Many comics have been developed to examine such as different topics as science, history, politics, and biography, and they have proven to be an excellent instructional tool.

f) Science-Fiction/Fantasy

Comics offer a plethora of interesting settings to explore for those who enjoy fantasizing about other realms.

g) Horror

In comics with eerie visuals and suspense-building plots, frights, shivers, and thrills abound.

\section{Research Methodology}

In this study, the researchers used the methodology of qualitative research because this research focused on the analysis of the written text. According to Bogdan and Biklen (2007:5) cited in Silalahi (2015), qualitative research is a research where data are collected in the form of words or pictures rather than numbers (Van Thao, Herman, \& Tho, 2020; Munte, Herman, Arifin, Nugroho and Fitriani, 2021). The data of this research was taken from the documentary or written form and library research because some of the data was taken from several websites which cannot be expressed numerically. Purba and Herman (2020) state that a qualitative approach is used for the description of the empirical data. One of the characteristics of qualitative method is looking at our processes that have to deal with arrangements, specifically, where the research will be conducted outside (Herman, Murni, Sibarani, \& Saragih, 2019).

According to Ary, Jacob, and Sorensen (2010), there are seven types of qualitative research. These are case studies, content or document analysis, ethnographic studies, which are grounded theoretical studies, historical studies, narrative research, phenomenological research. That researchers use content or document analysis. According to Ary et al. (2010), content or document analysis is a research method applied to written or visual material for the purpose of identifying specific material characteristics. Theory analyzed can be in the form of textbooks (comics), newspapers, web pages, speeches, television programs, advertisements, musical compositions, or one of a number of other types of documents (Van Thao, Herman, Napitupulu, Hien, \& Pardede, 2021) because the researchers chose comics as the object of research. As we know, comic files have sentences or dialogues that can be analyzed.

\subsection{Source of the Data}

Data sources that are relevant to the research problem must be identified by researchers. Researchers used comic Hunter X Hunter by Yosihihiro Togashi as a primary source for this study. Researchers used e-comics, also known as electronic comics that were downloaded from the internet. Data collection from this research was taken from 3 chapters, namely from chapter one to chapter three. This primary source was chosen because in the comics there are several sentences that had sentence fragments, so the researchers wanted to examine what types of sentence fragments based on syntactic structure were there, and what factor types were causing them.

\subsection{Instruments of the Research}

Research instrument is a tool used by researchers to measure or collect descriptive information as a processing material relating to the measuring object being studied. Simbolon, Sihombing, Herman, and Marpaung (2020) stated that instrument is a tool that is required to get information while Sihombing as cited in Hutabarat et al. (2020) stated that comics is designed to collect the data. The researchers themselves were the main instrument of the reseach, but to make the research process easier, the researchers needed supporting instruments such as internet, e-comic, cellphones, digital dictionaries, and laptop. In this study, the researchers employed comics as an instrument, namely Yosihihiro Togashi's Hunter X Hunter1998. With the term comic, the author intends to raise the anime in "Hunter X Hunter" to describe the life of a 12-year-old kid named Gon Freecss, and his efforts to find his father, Ging Freecss. The comic was first released by Shueisha on June 4, 1998 in Japan. These comics were gained through the use of e-comics, which were downloaded from the internet.

\subsection{Technique of Data Collection}

According to Marshall (2006:97) as cited in Sinaga, Herman, Hutahaean, and Niswa (2020), participating in the setting, witnessing personally, conducting in-depth interviews, and examining documents and material culture are all common qualitative ways for acquiring information. The data was gathered with the help of documentation. The comic is the source of the data that will be evaluated by the researchers during data collecting. The information is presented in the form of dialogue from the comic. The researchers will examine 20 interviews in order to determine the phrase fragments in the cartoon. 
There are several steps to collect data in this research:

1. Downloading the comic Hunter X Hunter from internet.

2. Reading the Comic Hunter X Hunter;

3. Finally, finding the types of Sentence Fragments in the text.

\subsection{Technique of Data Analysis}

According to Simbolon et al. (2020), data analysis is an important part of research. Data analysis is the process by which the researchers perfect their knowledge of the primary source to clearly present what they learn from it to their audience (James, 2010:224 cited in Simbolon et al. (2020)). In this study, researchers analyzed comics based on data. The data was analyzed according to Choy and Clark (2010) in Nurhusna (2012), there are several types of sentence fragmentation. In this study, researchers used comic Hunter X Hunter by Yoshihiro Togashi 1998 for data analysis techniques.

In this analysis, some steps in order to make this analysis systematic and easier, they are:

1. Reading the contents of the comic chapter several times, in order to understand each sentence in the comic dialogue.

2. Marking up comics when they find the data you are looking for (researchers analyzed sentence fragment) or find sentence fragments that are in comics.

3. Analyzing the types of sentence fragments included in the comic dialogue.

4. Analyzing what factor types the dialogue has as sentence fragments.

5. Concluding what types of sentence fragments and factor types are in the comic.

\section{Findings and Discussion}

\subsection{Findings}

In this chapter, the researchers classified the data based on the types and the factors of the sentence fragments. The researchers found some various types of sentence fragment and factors of sentence fragment. For the types and factor of sentence fragment, the researchers analyzed by using theory of Choy and Clark (2010). and Bashir et al. (2016) theory.

1. Types of Sentence Fragments

The appendix shows that there are several types of sentence fragments in the Hunter X Hunter comic by Yoshihiro Togashi 1998. There are 34 various types of sentence fragments contained. There are 13 types that are classified as dependent clause fragments, and 21 as phrase fragments.

Table 1. Types of Sentence Fragment

\begin{tabular}{|l|l|l|l|}
\hline & Sub types & Frequency & Percentage \\
\hline \multirow{5}{*}{ Dependent-Clause Fragment } & ACF & 1 & $2,94 \%$ \\
\cline { 2 - 4 } & AdCF & 6 & $17,64 \%$ \\
\cline { 2 - 4 } & NCF & 6 & $17,64 \%$ \\
\hline \multirow{5}{*}{ Phrase Fragment } & ADF & - & - \\
\cline { 2 - 4 } & AF & 1 & $2,94 \%$ \\
\cline { 2 - 4 } & IPF & 10 & $29,94 \%$ \\
\cline { 2 - 4 } & MSF & 3 & $8,82 \%$ \\
\cline { 2 - 4 } & PPF & 6 & $17,64 \%$ \\
\cline { 2 - 4 } & PrPF & 1 & $2,94 \%$ \\
\hline & Total & 34 & $100 \%$ \\
\hline
\end{tabular}




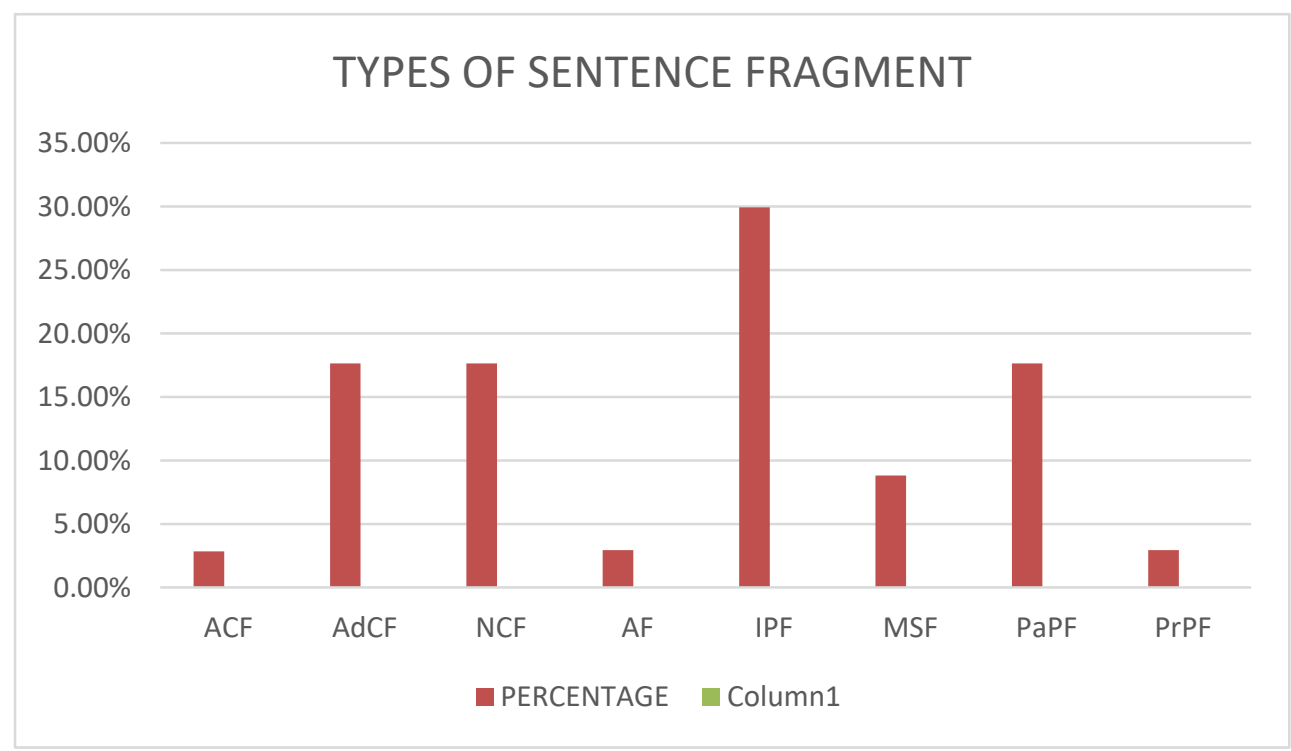

Chart 1. Types of Sentence Fragment based on Comic Hunter X Hunter by Yoshihiro Togashi 1998

The data above shows the quantitative measures for the two types of Sentence Fragments. Dependent Clause Fragment type was $38 \%$ while Phrase Fragment type was $62 \%$. So the dominant type of Sentence Fragment in Yoshihiro Togashi's 1998 comic Hunter X Hunter is the Phrase Fragment.

2. Factor Sentence Fragment

Researchers classified sentence fragment factors according to Bashir et al. (2016). There are 10 types of factors that make sentence fragments occur; namely, Omission of Verb, Omission of Subject, Omission Subject and Verb, Omission of Object, Dependent Clause Fragment, Appositive or list Fragment.

Table 2. The Percentage of Factors Sentence Fragment

\begin{tabular}{|l|l|c|c|}
\hline No. & Factor of Sentence fragment & Frequency & Percentage \\
\hline 1. & Omission of verb & 5 & $50 \%$ \\
\hline 2. & Omission of Subject & 2 & $20 \%$ \\
\hline 3. & Omission both Subject and Verb & 1 & $10 \%$ \\
\hline 4. & Omission of Object & - & $10 \%$ \\
\hline 5. & Dependent Clause Fragment & 1 & - \\
\hline 6. & Appositive or list Fragment & 10 & $10 \%$ \\
\hline & Total & & $100 \%$ \\
\hline
\end{tabular}




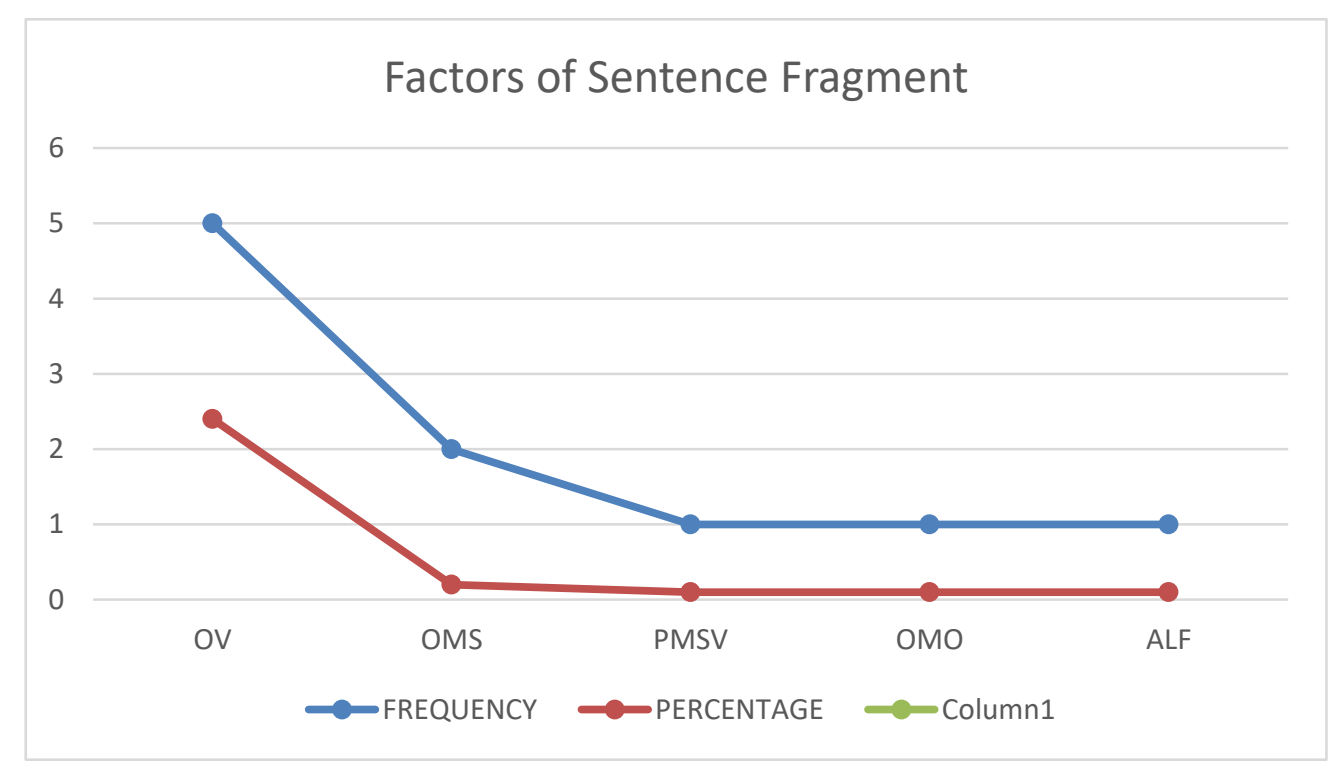

Chart 2. Factors of Sentence Fragment based on Comic Hunter X Hunter by Yoshihiro Togashi 1998

From the data analysis above, we can see the Factor of Sentence Fragment in the Comic Hunter $x$ Hunter from the chapter 1 until 30. According to Bashir et al. (2016)'s theory, there are 50,00\% data included for the Omission of Verb, $20 \%$ for the Omission of Subject, and 10\% data included for the Omission both Subject and Verb. In addition, there are $10 \%$ data included for the Omission of Object, and no data included for Dependent Clause Fragments, and $10 \%$ included for the Appositive phrase or list Fragment. From this research, the factor that have the highest value in forming sentence fragments in the Hunter x Hunter comic is the Omission of Verb.

\subsection{Discussion}

After analyzing the data, the researchers were able to arrive at the conclusion that almost all types of sentence fragments are contained in the comic, but with the exception of only one type of fragment, namely Added - detail Fragment. The dominant type is the Phrase Fragment which reaches $62 \%$ of all fragments used in the text. This means that Phrase Fragment is the most typical one in the comic. However, Dependent Clause fragment only reached $38 \%$.

Researchers also found the sentence fragment factor contained in the comic hunter $\mathrm{x}$ hunter by Yoshihiro Togashi. There are 6 types of sentence Fragment factors that were put forward by Bashir et al. (2016), but in the hunter $\mathrm{x}$ hunter comic only 4 factors were found, namely, Omission of Verb (50\%), Omission of Subject (20\%), Omission of Object (10\%). Omission of both subject and verb is (10\%), and Appositive or list Fragment (10\%).

Researchers found several similarities and differences with the results of other studies. There are various parallels and variations in the study undertaken by researchers based on the results of prior research with the title "Sentence Fragments in the Narration of the novel Hungers Game by Nurhusna." Both studies use qualitative research methods to examine sorts of sentences based on Fragment, its syntactic structure, and the second equation employs both the Choy and Clark theories for the analysis of these fragments. As a difference, among other things, in previous studies, researchers used qualitative methods while this study used qualitative research document studies. The second difference from the results of the previous research was that the researchers only examined the type of sentence fragments based on its syntactic structure whereas in our study we examined the type based on the syntactic structure and the factors that made sentence fragment occur in a sentence. The difference between the three previous studies has research results consisting of 46 dependent-clause fragments (33\%) and 92 the phrase fragments were (67\%), while this study had 13 dependent clause fragments (38.22\%) and 21 Phrase fragments (62.28\%).

\section{Conclusions}

Referring to the data analysis and findings that have been made, the researchers come to the following conclusions:

1) Based on the findings of the Sentence fragments in the Hunter $x$ Hunter by Yoshihiro Togashi comic, several types of Sentence Fragments are classified into two types according to the theory of Choy and Clark (2010) which contains each subtype. These types are Dependent Clause Fragments and Phrase 
Fragments. The data found in comic Hunter x Hunter are 34 fragments. They can be classified into dependent clause fragment (13) and Phrase Fragment (21). From the study, the researchers concluded the highest number of types Sentence fragment based on syntactic structure is Phrase Fragment 21(62\%), the fewest number of sentence fragment based on Syntactic structure is Dependent Clause Fragment which had $13(38 \%)$ samples. The factor of Sentence Fragment was also detected in the comic. The researchers had analyzed it based on the Bashir's theory.

2) The factor Sentence Fragment had been found in Hunter x Hunter Comic is Omission Verb, Omission Subject, Omission Object, and Appositive or list Fragment. According to the findings, the largest number of Sentence Fragments is Omission Verb (5 examples), Omission Subject (2), Omission both Subject and Verb (1), Omission Object (1), Dependent Clause Fragment (1), Appositive or list Fragment (1).

\section{References}

Al Kayed, M., Khalaf, S., \& Akram, M. (2020). Critical discourse analysis of gender representations in EFL textbooks. International Journal of English Language and Literature Studies, 9(4), 244-254. https://doi.org/10.18488/journal.23.2020.94.244.254

Anker, S. (2010). Real writing with readings: Paragraphs and essays for colleges, works, and everyday life (5th ed.). Boston: Bedford/St. Martin's.

Arifa, F. (2016). Analysis of elements of Indonesian online comics as a medium for spreading culture. Thesis. Palembang: State Islamic University.

Arsyat. (2014). Analysis of elements of Indonesian online comics as a medium for spreading culture. Essay. Palembang: State University of Indonesia.

Ary, D., Jacob, L., \& Sorensen, C. (2010). Introduction to research in education (8th ed.). Boston: WARDSWORTH Cengage Learning.

Bashir, I., Yusof, N. B., Ahmad, N. S., \& Syed Umar, S. N. M. B. (2016). Sentence fragmentation in the writing of senior secondary school students of Gwale, Kano, Nigeria. Schoolar Journal of Arts, Humanities and Social Sciences, 4(9A), 9921000.

Choy, P., \& Clark, D. G. (2010). Basic grammar and usage (8th ed.). Boston, MA: Cengage Learning.

Herman. (2016). The method of translation and practices. Deutschland/Germany: LAP Lambert.

Herman. (2017). Shift in translation from English into Indonesia on narrative text. International Journal of European Studies, 1(3), 72-77.

Herman, Murni, S. M., Sibarani, B., \& Saragih, A. (2019). Structures of representational metafunctions of the "Cheng Beng" ceremony in pematangsiantar: A multimodal analysis. International Journal of Innovation, Creativity and Change, 8(4), 34-46.

Herman, Purba, R., Thao, N. V., \& Purba, A. (2020). Using genre-based approach to overcome students' difficulties in writing. Journal of Education and E-Learning Research, 7(4), 464-470. https://doi.org/10.20448/journal.509.2020.74.464.470

Hutabarat, E., Herman, H., Silalahi, D. E., \& Sihombing, P. S. R. (2020). An analysis of ideational metafunction on News Jakarta post about some good Covid-19 related news. VELES Voices of English Language Education Society, 4(2), 142-151. https://doi.org/10.29408/veles.v4i2.2526

Kolln, M., \& Funk, R. (2011). Understanding English grammar (9th ed.). England: Longman.

Liasari, A. (2015). An analysis of Indonesia-English code mixing used in Spotlite Rubric. on Cita Cinta Magazine. IAIN Salatiga. Editions (July-September 2015).

Mahayani, T., Chodijah, S., \& Ainiyah, A. (2018). Improving syntax learning achievement through lesson study based learning on IV semester students of Indonesian language and letter education study program Pakuan University. Journal of Humanities and Social Studied, 2(1), 12-17. https://doi.org/10.33751/jhss.v2i1.815

Munte, B., Herman., Arifin, A., Nugroho, B. S., \& Fitriani, E. (2021). Online Student Attendance System Using Android. Journal of Physics: Conference Series. 1933012048. https://doi.org/10.1088/1742-6596/1933/1/012048

Nurhusna, F. (2012). Sentence fragments in the narration of the novel the hunger games. Lexicon, 1(2), 164-175. 
https://doi.org/10.22146/lexicon.v1i2.42075

Pardede, H., \& Herman, H. (2020). The effect of numbered heads together method to the students' ability in writing recount text. Cetta: Jurnal Ilmu Pendidikan, 3(2), 291-303. https://doi.org/10.37329/cetta.v3i2.455

Purba, R., \& Herman. (2020). Multimodal analysis on Ertiga car advertisement. Wiralodra English Journal, 4(1), 21-32. Available at: https://doi.org/10.31943/wej.v4i1.77

Salor, \& Marasligil. (2013). Translating comics. In Norwich Paper (Vol. 21): University of East Anglia.

Silalahi, D. E. (2015). The English learners' comprehension on figurative language at FKIP UHN Pematangsiantar. Journal of English Department, 2(3), 60-69.

Simbolon, C., Sihombing, P. S. R., Herman, \& Marpaung, T. I. (2020). An analysis of deixis on the song lyrics of Ed Sheeran "Divide” album. Global Science Journal, 8(9), 1363-1382.

Sinaga, D. A., Herman, Hutahaean, D. T., \& Niswa, K. (2020). Semantic analysis on idiomatic expression in the "central intelligence" movie. European Exploratory Scientific Journal, 4(3), 10-19.

Sinaga, H., Herman, \& Pasaribu, E. (2020). The effect of anagram game on students' vocabulary achievement at grade eight of SMP Negeri 8 Pematangsiantar. Journal of English Educational Study, 3(1), 51-60. https://doi.org/10.31932/jees.v3i1.655

Soedarso, N. (2015). Comics: Illustrated literary works. Humanities, 6(4), 496-506. https://doi.org/10.21512/humaniora.v6i4.3378

Van Thao, N., Herman, Ha, T. T., Thuy, N. T. T., \& Tho, N. T. Q. (2020). Analysis of argumentation in Nam Cao's Story 'Chi Pheo' based on a pragmatics perspective. International Journal of Innovation, Creativity and Change, 12(12), 931-948.

Van Thao, N., Herman, Napitupulu, E. R., Hien, N. T., \& Pardede, H. (2021). Code-switching in learning via zoom application: A study in an EFL context. Asian ESP Journal, 17(3.1), 91-111.

Van Thao, N., Herman, \& Tho, N. T. Q. (2020). A comparative study of words indicating 'artificial containers of water' in Vietnamese and English. International Journal of Innovation, Creativity and Change, 12(10), 328-337.

Wu, Y., \& Pei, Z (2018). An Investigation of Critical Thinking Manifested in the Questions of EFL Textbooks for Tertiary-Level English Majors of China. American Journal of Education and Learning, 3(2), 72-84. https://doi.org/10.20448/804.3.2.72.84

Yang, P. L. (2019). Investigating the impact of English picture books on EFL learners anxiety in Taiwan. Humanities and Social Sciences Letters, 7(2), 56-63. https://doi.org/10.18488/journal.73.2019.72.56.63

Yaqin, A. M. L. (2020). An analysis of sentence fragments in the students' writing the Third Semester of English Department of UMMAT in Academic Years 2019/2020. Thesis Unpublished. Mataram: Muhammadiyah University Mataram University.

\section{Copyrights}

Copyright for this article is retained by the author(s), with first publication rights granted to the journal.

This is an open-access article distributed under the terms and conditions of the Creative Commons Attribution license (http://creativecommons.org/licenses/by/4.0/). 